\title{
A importância da Educação Infantil para o pleno desenvolvimento da criança
}

\author{
The importance of Early Childhood Education for the full development of the child
}

Stefânia da Silva ${ }^{\dagger}$, Stephanie Souza Monteiro ${ }^{\dagger}$, Marinéa Figueira Rodrigues :* $^{*}$

Como citar esse artigo. Rodrigues, M.F. A importância da Educação Infantil para o plenodesenvolvimentodacriança. Revista Mosaico. 2017 Jul./Dez.; 08 (2): 30-38.

\begin{abstract}
Resumo
O presente estudo objetivou investigar a importância da Educação Infantil para o pleno desenvolvimento da criança, enfatizando o lúdico como recurso de extremo valor nessa empreitada, tomando por base, pesquisas bibliográficas de renomados autores, como: Ariès (1981), Almeida (2003), Silva (2009), Oliveira (2010), Kramer (2011) e Rau (2011) dentre outros. Inicialmente, desenvolveu-se uma reflexão sobre a infância em épocas passadas, passeando pela Idade Média até os dias atuais. A seguir, foi realizado um breve resumo sobre a Educação Infantil e a sua função pedagógica. Posteriormente, caracterizou-se o lúdico como ferramenta pedagógica na formação da criança, explicitando a sua relevância na escola e para o educador.

Palavras-Chave: Criança; Desenvolvimento; Educação Infantil; Lúdico.
\end{abstract}

\begin{abstract}
The present study aimed to investigate the importance of Early Childhood Education for the full development of the child, emphasizing play as a resource of extreme value in this endeavor. Based on the bibliographical research of renowned authors such as Ariès (1981), Almeida (2003), Silva (2009), Oliveira (2010), Kramer (2011) and Rau (2011) among others. Initially, a reflection on childhood was developed in past seasons,going through the Middle Ages to the present day. The following is a brief summary on Early Childhood Education and its pedagogical function. Subsequently, play was characterized as a pedagogical tool in the formation of the child, explaining its relevance in the school and for the educator.

Keywords: Child; Development; Child education; Playful.
\end{abstract}

\section{Introdução}

O presente artigo visa conceituar a importância do lúdico no pleno desenvolvimento infantil, para proporcionaruma aprendizagem prazerosa e significativa para o desenvolvimento da criança.

Segundo Antunes (2010, p. 9), "a Educação Infantil é tudo; o resto, quase nada". Essa frase é indiscutivelmente verdadeira, pois é um período em que a criança está em constante ebulição de suas habilidades cognitivas, mentais, afetivas e psicomotoras, sendo, portanto, um período de muitas descobertas.

As crianças, como seres ativos, podem se tornar cada vez mais competentes para lidar com as coisas do mundo, se tiverem oportunidades para isso, já que vivemos em contextos culturais e históricos em permanente transformação. Por isso, é de suma importância defender o direito da criança à infância, ao brinquedo, ao sonho e à fantasia de viver num mundo que é apenas seu.

\section{Conceito de Infância: aspectos históricos e contemporâneos}

Durante muito tempo a educação da criança pequena foi considerada de pouca importância, pois era necessário apenas que tivesse o básico para sua sobrevivência, cuidados e alimentação.

O termo infância, como qualquer outra fase da vida, é constituído em função das mudanças sofridas pela sociedade. No decorrer da história da

Afiliação dos autores: † Discentes da Universidade Severino Sombra - USS, Vassouras-RJ, Brasi

$\$$ Docente da Universidade Severino Sombra - USS, Vassouras-RJ, Brasil.

*marinea.rodrigues@hotmail.com 
humanidade, o tratamento dispensado as crianças e a forma de entender o seu universo sofreram mudanças substanciais ao longo dos séculos.

Durante a Idade Média, não existia qualquer concepção de infância que distinguisse a criança do adulto, já que a mesma era considerada um adulto de pequeno tamanho que executava as mesmas atividades que as pessoas mais velhas (ARIÈS, 1981).

"Uma série de práticas sociais como jogos, ocupações, trabalhos, profissões e armas, não estavam determinadas para idade alguma. As crianças eram vestidas como homens e mulheres tão logo pudessem ser deixadas as faixas de tecido que eram enroladas em torno de seu corpo quando pequenas. Não existia o atual pudor às crianças a respeito de assuntos sexuais"(KOHAN, 2005, p. 65).

Corroborando tais ideias, Kohan (2005) explicita que as crianças, tal como as compreendemos nos dias atuais, permaneciam pouco tempo no âmbito da família.

\begin{abstract}
"Tão logo o pequeno pudesse prover-se fisicamente, habitava o mesmo mundo que os adultos, confundindose com eles. Nesse mundo adulto, aqueles que hoje chamamos crianças eram educadas sem que existissem instituições especiais para eles. Tampouco, também não existia concepção de adolescência ou de juventude: os pequenos passavam diretamente de bebês a homens (ou mulheres) jovens. Não havia, naqueles tempos, nenhuma ideia ou percepção particular ou específica da natureza da infância diferente da vida adulta." (KOHAN, 2005, p. 64).
\end{abstract}

Nessa época, a infância era vista como uma transição para a vida adulta, onde tratamentos diferenciados com relação à criança eram totalmente descartados, o que contribuía para o aumento da mortalidade infantil. Segundo Faria (1997, p. 11) "para a sociedade medieval, o importante era a criança crescer rapidamente para poder participar do trabalho e de outras atividades do mundo adulto."

"A duração da infância era reduzida ao seu período mais frágil, enquanto o filhote do homem ainda não conseguia bastar-se; a criança então, mal adquiria algum desembaraço físico, era logo misturada aos adultos, e partilhava de seus trabalhos e jogos. De criancinha pequena, ela se transformava imediatamente em homem jovem, sem passar pelas etapas da juventude, que talvez fossem praticadas antes da Idade Média e que se tornaram aspectos essenciais das sociedades evoluídas de hoje." (ARIÈS, 1981, p.10).

Durante esse período, o trabalho doméstico constituía uma forma comum de educação, tanto para os ricos como para os pobres, a criança aprendia através da prática de modo que, a partir dos sete anos de idade, todas as crianças independentemente de suas condições sociais eram colocadas em famílias estranhas para que assim pudessem aprender os serviços domésticos.
A transmissão dos valores e dos conhecimentos, e de modo mais geral, a socialização da criança, não eram, portanto, nem asseguradas nem controladas pela família. A criança se afastava logo de seus pais, e pode-se dizer que durante séculos a educação foi garantida pela aprendizagem, graças à convivência da criança ou do jovem com os adultos. A criança aprendia as coisas que devia saber ajudando os adultos a fazê-las. (ARIÈS, 1981, p.10).

Na Idade Média, além de não existir sentimentos adequados e direcionados às crianças, também não havia trajes reservados a infância obrigando-os a se vestirem como os adultos, quando apenas se diferenciavam as roupas de acordo com os degraus de hierarquia social (ÀRIES, 1981).

A escola, por sua vez, contribuía para o ingresso da criança no mundo dos adultos já que as aulas eram frequentadas por estudantes de todas as idades, pois se achava natural os adultos e crianças assistirem a mesma aula, levando em consideração que o importava era o conteúdo a ser ensinado.

A concepção de infância, que temos hoje, como um período da vida ou uma fase que suscita uma atenção diferenciada do adulto e, por isso, merece receber um cuidado específico, tem seu nascedouro na modernidade.

"Essa forma de conceber a infância tem suas origens durante o século XVI e XVII e, portanto, é na Idade Moderna que se concede à criança uma atenção que outrora em nossa história não existia. "(SILVA, 2009, p. 12).

\section{E conpleta,}

"[...] Ao mesmo tempo em que podemos afirmar o nascimento da ideia de sua negação, à medida que a infância passa a ser pensada como uma fase, um período e, portanto, uma condição que deve ser superada ou substituída pela racionalidade adulta." (SILVA, 2009, p. 12).

Corroborando tais ideias, Gagnebin (1997) afirma que é no século XVIII que tem início a ideia de infância como uma idade profundamente singular a ser respeitada em suas diferenças.

Apesar das poucas mudanças significativas ocorridas até o século XVIII, no que diz respeito ao padrão filantrópico e assistencial das políticas públicas, podemos perceber registros das primeiras iniciativas de atendimento à infância, através do contexto da Revolução Industrial, do Iluminismo e da Constituição dos Estados Laicos (FARIA, 1997).

“[...] a ideia de infância surge no contexto histórico e social da modernidade, com a redução dos índices de mortalidade infantil graças ao avanço da ciência e a mudanças econômicas e sociais. Sabemos que a idéia de infância, da maneira como hoje a conhecemos, nasceu no interior das classes médias que se formavam no interior da burguesia. (KRAMER, 2003, p. 87)." 
Faria (1997) afirma que a transição do Feudalismo para o Capitalismo na Europa Ocidental acarretou grandes alterações nas relações sociais que refletiram na organização familiar, escolar e no sentimento de infância. A criança passa a ser fonte de alegria para os adultos surgindo sentimentos de dor e piedade, passando a ser considerada como ser frágil e ameaçado, conquistando cuidados e atenção. Ariès (1981) afirma que se tratava de um sentimento inteiramente novo: os pais se interessavam pelos estudos de seus filhos e os acompanhavam com uma solicitude habitual nos séculos XIX e XX, mas outrora desconhecida.

"A família começou então a se organizar em torno da criança
e a lhe dar uma tal importância, que a criança saiu de seu
antigo anonimato, que se tornou impossível perdê-la ou
substituí-la sem uma enorme dor, que ela não pôde mais ser
reproduzida muitas vezes, e que se tornou necessário limitar
seu número para melhor cuidar dela." (ARIÈS, 1981, p.12)

Segundo Kramer (2011), a noção de infância surge da consciência de distinguir a criança do adulto e não com a intenção de afetividade. O surgimento de um novo tipo de sentimento dedicado à criança contradiz as atitudes que caracterizam o comportamento dos adultos, considerando-a ingênua, inocente e graciosa - tomada pela paparicação.

Mas a paparicação, no século XVII, é julgada como prejudicial de maneira que tornava as crianças mimadas e mal-educadas; sendo assim, propõe-se uma educação de moralização das mesmas, cujo objetivo era torná-las pessoas honradas e homens racionais. Assim a criança abandona o ser divertido e agradável, passando a ser educada, substituindo a aprendizagem de caráter empírico e adquirindo a forma pedagógica realizada nas escolas através do ensino de teorias de ofícios. "Esta aproximação pais-criança gerou um conceito de família e de infância que outrora não existia, e a criança tornouse o centro das atenções, pois a família começou a se organizar em torno dela". (FARIA, 1997, p.13).

Durante esse período, tornou-se comum o uso de castigos corporais para a correção dos estudantes, tanto nas escolas, quanto nas famílias. Este procedimento somente podia ser aplicado à plebe, já que era considerada como uma prática degradante aos fidalgos, o que fez com que formas de autoridade social fossem produzidas, onde os mais poderosos dominavam os mais fracos.

Também nessa época foi criado um traje, diferenciado dos adultos, para as crianças e entre homens e mulheres, quando cada traje passa a ser discriminado com relação à idade e a condição social.

Com a separação da criança do mundo adulto, deu início ao prolongamento da primeira infância, passando a idade escolar para os 10 anos de idade, sendo criado também um ensino diferenciado entre as classes burguesa e aristocrática -, o que alimentou o crescimento da discriminação social no sistema educacional.

No final do século XVIII e início do XIX, o entendimento que até então se tinha da criança foi progressivamente se modificando e a concepção de infância como uma etapa distinta da vida se consolidou na sociedade. Essa percepção, de acordo com Ariès (1981), se deu concomitante à constituição da família nuclear, do estado nação e da nova organização do trabalho produtivo.

A criança viu-se, então, excluída do mundo do trabalho e de responsabilidades, rompendo com o mundo dos adultos, não participando mais de atividades nas quais até então a sua presença era habitual (ARIĖS, 1981).

Segundo Corsaro ${ }^{1}$ (2003 apud NASCIMENTO, BRANCHER e OLIVEIRA, 2008), a instituição escola foi crucial para que o conceito de infância começasse a ser alterado, por meio da escolarização das crianças. Pode-se, então, a partir do desenvolvimento de uma pedagogia para os pequenos, falar numa construção social da infância.

A sociedade contemporânea vive dividida em espaços exclusivos, existindo a separação em faixas etárias: crianças, adolescentes, adultos jovens e adultos velhos que ocupam áreas reservadas, como creches, escolas, oficinas, escritórios, asilos, locais de lazer etc. Mas é no contexto familiar que ocorrem mais frequentemente os encontros entre as gerações, ao menos por proximidade física, embora muitas vezes prevaleça o distanciamento afetivo. Esse distanciamento afetivo leva os especialistas à discussão da qualidade das relações estabelecidas, uma vez que a família é considerada uma instância formadora de novos cidadãos, embora muito criticada nos últimos anos (ADATTO, 1998).

Já Oliveira (2010) argumenta que a grande expansão tecnológica experimentada no século XX trouxe mudanças significativas na educação dos pequenos. O próprio trabalho das mulheres no lar foi modificado mediante a utilização crescente de eletrodomésticos e de alimentos pré-fabricados. Mães com maior conhecimento na área educacional passaram a redefinir cada vez mais suas tarefas em relação à educação de seus filhos, pois surge a preocupação de controlar o ambiente da criança pequena de modo que lhe fosse garantido um bom desempenho psicológico.

Sociólogos e Antropólogos também contribuíram muito para que a educação dos pequenos fosse pensada e sofresse transformações. Os sociólogos afirmavam que a força da estrutura social era determinante nas oportunidades cotidianas das crianças; já os antropólogos destacaram como culturas diferentes elaboravam suas concepções e práticas educativas, abrindo novos horizontes para maior flexibilização e inovação dos modelos de educação Infantil. 
Oliveira (2010, p. 81), ainda reconhece que, nessa atual etapa, a infância é um direito inalienável de toda criança. Portanto:

\begin{abstract}
"Trata-a como um 'sujeito social' ou 'ator pedagógico' desde cedo, agente construtor de conhecimentos e sujeito de autodeterminação, ser ativo na busca do conhecimento, da fantasia e da criatividade, que possui grande capacidade cognitiva e de sociabilidade e escolhe com independência seus itinerários de desenvolvimento".
\end{abstract}

Atualmente, na Europa, a forma de trabalhar com as crianças em idade anterior à da escolaridade obrigatória, é muito diferente de um país a outro. Mas os objetivos que vem sendo buscados pela maioria das instituições responsáveis pela educação infantil são o desenvolvimento da criança sob todos os aspectos: físico, cognitivo e afetivo - a aprendizagem de diferentes meios expressivos e o preparo para a escola elementar, sem esquecer a função de guarda, como componente essencial das metas do atendimento em questão. (OLIVEIRA, 2010).

Segundo Dolto (1993), as crianças dos dias atuais são escolarizadas muito cedo, e muitas, inclusive, desde os primeiros meses de vida, são recolhidas em creches (todos os dias) ou em instituições semelhantes, porque pais e mães trabalham o dia todo. Inúmeras crianças vivem permanentemente internadas em estabelecimentos especializados, na falta de pais ou de pessoas responsáveis.

Mudanças na realidade econômica e o acesso dos pequenos à informação sobre o mundo adulto, transformou radicalmente a infância. A literatura recente sobre o tema, tanto na imprensa popular quanto na escolar, expõe a "perda da infância" "crianças crescendo muito rápido" e "terror das crianças no isolamento dos lares e comunidade fragmentados". (KINCHELOE, 2004, p.13).

A nossa sociedade atual tem distanciado cada vez mais as crianças dos adultos, inclusive segregando-as das interações entre elas mesmas. A instituição escolar tem sido considerada a responsável pela formação dessa criança praticamente em tempo integral. Daí a grande responsabilidade dos profissionais de educação, no sentido de estarem atentos a essas mudanças no que diz respeito ao entendimento da infância, "não só como essa infância está sendo pensada, mas também como ela está sendo vivida pelas crianças no nosso mundo considerado globalizado".(SILVA, 2009, p. 41).

Podemos acrescentar, ainda, como iniciativa das políticas públicas brasileiras, a Lei de Diretrizes e Base da Educação (LDB), como também outras legislações recentes a respeito da infância, que são consequências da Constituição Federal de 1988 que definiu uma doutrina em relação à criança como um sujeito de direitos.

Com a Constituição Federal de 1988 (BRASIL, 1988) ficou legalmente definido que os pais, a sociedade e o poder público têm que garantir os direitos da criança, como se traduz no artigo 227 :

É dever da família da sociedade e do Estado assegurar a criança e ao adolescente com absoluta prioridade, o direito à vida, à saúde, à alimentação, à educação, ao lazer, à profissionalização, a cultura, à dignidade, ao respeito, à liberdade e à convivência familiar e comunitária, além de colocá-los a salvo de toda formação de negligência, discriminação, exploração, violência e opressão. (CRAIDY; KAERCHER, 2001, p. 24).

Encontramos também, o Estatuto da Criança e do Adolescente (ECA), Lei Federal 8.069/1990, que explicitou os direitos e os deveres da criança e do adolescente, como também os princípios que devem orientar as políticas de atendimento, determinando também a criação dos Conselhos da Criança e do Adolescente (traçam as diretrizes políticas) e dos Conselhos Tutelares (zelam pelo respeito aos direitos das crianças e adolescentes, entre eles à educação). (BRASIL, 1990)

Craidy e Kaercher (2001, p. 24) asseguram que a LDB, no seu Artigo 21, inciso I, define a Educação Infantil como a primeira etapa da educação básica "e que, tem por finalidade o desenvolvimento integral da criança [...], em seus aspectos físicos, psicológico, intelectual e social, complementando a ação da família e da comunidade".(Art. 29).

\section{Consolidando a Educação Infantil}

Segundo Barbosa et al. (2012, p.15), "a educação infantil (EI) brasileira, primeira etapa da educação básica, constitui um campo de ações políticas, práticas e conhecimentos em construção, procurando demarcar-se de um passado antidemocrático". A Educação Infantil está integrada, legalmente, ao sistema de ensino desde 1996 e compreende as creches para crianças de até 3 anos e 11 meses de idade e as pré-escolas para crianças de 4 a 5 anos e 11 meses de idade.

\section{Educação Infantil: breve histórico}

Historicamente, é possível perceber que a Educação Infantil surge em forma de creche, como um refúgio assistencial para a população infantil que durante muito tempo foi desprovida de cuidados domésticos e vista com olhares de rejeição e desprezo, construindo, assim, um retrato de uma infância desolada de sua sociedade e de sua cultura específica.

Faria (1997, p. 24) explicita que durante o século XIX, "a constituição das instituições pré-escolares (creches, jardins de infância e asilos) teve um cunho assistencialista e foi sustentada por influências médicohigienista, jurídico-policiais e religiosas". Portanto, 
a assistência à infância se deu pela junção de forças jurídicas, empresariais, políticas, médicas, pedagógicas e religiosas. Sendo que esse atendimento teve maior destaque no viés médico e sanitário, em virtude do movimento higienista, embora não tenha sido preponderante nesta época.

Na história das instituições pré-escolares, estão presentes a temática infância, modernidade e trabalho feminino, pois estes temas e as próprias instituições préescolares se relacionam com o processo de construção da sociedade capitalista, da urbanização e da organização do trabalho na indústria.

Com a valorização gradativa da infância e o reconhecimento da necessidade de atendê-la, a creche surge apenas como substituta corresponsável pela educação dos pequenos.

\begin{abstract}
"A urbanização, a crescente participação da mulher no mercado de trabalho extradomiciliar e as alterações na estrutura familiar são ainda hoje fatores determinantes da demanda social de creches e pré-escola. [...] Quando surge uma creche ou pré-escola, nova perspectiva abrese para a mulher e para a criança, o melhor, para toda a família [...]. Mas a educação infantil não parou por aí. Várias ciências debruçaram-se sobre a criança, nos últimos cinquenta anos, entre elas a psicologia, a sociologia, a biologia e a psicanálise infantil." (DIDONET, 1991, p. 92).
\end{abstract}

No Brasil, com a crescente globalização e as mudanças da vida urbana na sociedade, as instituições de Educação Infantil foram se modificando. Porém, somente em 1875 é que surgiram as creches, as casas de infância, as escolas, os maternais e os jardins de infância, onde a Educação Infantil passa a integrar a criança e seu desenvolvimento; mas é a partir do século XIX que se enfatiza a importância da educação para o desenvolvimento social.

No início do século $\mathrm{XX}$, são implantadas as primeiras instituições pré-escolares assistencialistas no Brasil, sendo fundadas as primeiras creches e, posteriormente, os jardins de infância.

“A partir de todas essas mudanças as escolas infantis
tornaram-se espaços de grande importância para o
desenvolvimento e aprendizagem. Estas que estão
inseridas na Constituição de 1988, e que contemplam
o caráter educacional destas instituições, passando a
educação infantil a ser direito da criança e dever do
estado, cabendo a este manter e dar a educação infantil
uma constante integração e valorização com o cuidar, o
educar e o brincar, elementos fundamentais no processo
de ensino e aprendizagem infantil.” (SILVA, 2010, p.26)

ALei de Diretrizes e Bases da Educação Nacional, Lei $n^{\circ} .9394 / 96$, acarretou mudanças significativas para complementação de tais características educacionais trazendo a Educação infantil para Educação Básica, ampliando a sua importância no processo de desenvolvimento, integração, socialização e aprendizagem onde "a criança começa a ser vista como dona de uma infância que exige maior compreensão e investimento quanto aos aspectos que ela desenvolve [...]" (SILVA, 2010, p. 27).

A Educação Infantil recebeu um destaque na LDB, inexistente nas legislações anteriores. É tratada na Seção II, do capítulo II (Da Educação Básica), nos seguintes termos:

"Art. 29 A educação infantil, primeira etapa da educação básica, tem como finalidade o desenvolvimento integral da criança até os seis anos de idade, em seus aspectos físico, psicológico, intelectual e social, complementando a ação da família e da comunidade. Art. 30 A educação infantil será oferecida em: I - creches ou entidades equivalentes, para crianças de até três anos de idade; II - pré-escolas para crianças de quatro a seis anos de idade"

Segundo MORENO (2007, p. 55) “uma educação infantil que respeite direitos da criança em um espaço adequado, rico em estímulos,[...] em busca da construção de novos saberes e da descoberta do mundo a sua volta."

Para Fortuna (2005), ainda é preciso fazer uma reinvenção da infância, a reconhecendo como fase de extrema importância dentro do desenvolvimento infantil, havendo vários desafios a serem superados diante de seus direitos e deveres, de modo em que infância e inocência sejam mantidas como sinônimos de alegria e afetividade.

Segundo as Novas Diretrizes Curriculares Nacionais para a Educação Infantil (DCNEI, 2010), o Parecer CNE/CEB no 20/09 e a Resolução CNE/ CEB $n^{\circ} 05 / 09$, a função sociopolítica e pedagógica das instituições de Educação Infantil, se integra com a primeira etapa da Educação Básica, como diz a Lei no 9.394/96 no Artigo 22, cuja finalidade é: desenvolver o educando, assegurar-lhe a formação comum indispensável para o exercício da cidadania e fornecerthe meios para progredir no trabalho e em estudos posteriores. Estas finalidades devem ser adequadamente interpretadas em relação às crianças pequenas, pois nesta interação elas manifestam desejos e curiosidades em relação a tudo que se passa ao seu redor.

Relata, ainda, a qualidade dos princípios pedagógicos que se refere como um dos fatores fundamentais para o ensinar e o aprender, fatores estes que estão definidos no Referencial Curricular Nacional para a Educação Infantil (BRASIL,1998).

De acordo com o Referencial Curricular para a Educação Infantil (1998), a criança é um ser social e histórico que está em processo de formação, interagindo consigo mesmo e com o mundo.

No processo educativo e tendo em vista as necessidades das crianças, faz-se necessário:

"Intenções educativas que estabelecem capacidades que às crianças poderão desenvolver como 
consequência de ações intencionais do professor, o que auxilia na seleção de conteúdos e os meios didáticos a serem utilizados." (BRASIL, 1998, p.47).

Com base nesta citação, percebemos que uma estrutura adequada, possibilita segurança e flexibilidade na organização do trabalho do professor, de forma que permita o pleno desenvolvimento físico, afetivo, cognitivo, ético, estético, em relação interpessoal e inserção social da criança.

Corroborando tais ideias, Moreno (2007, p. 57) assegura que a ação pedagógica está relacionada no cuidar, no educar e no brincar, pois esses fatores são fundamentais para uma boa aprendizagem. Portanto, “o trabalho pedagógico na Educação Infantil deve priorizar os direitos da criança, o lúdico, sua curiosidade, seu desenvolvimento físico, cognitivo, afetivo e social etc."

\section{A importância da ludicidade na formação da criança}

Costa (2005), afirma que a palavra lúdico vem do latim ludus e significa brincar. Esse brincar abrange os jogos, brinquedos e brincadeiras e a palavra é relativa também à conduta daquele que joga, que brinca e que se diverte. Através do jogo, o sujeito adquire múltiplas possibilidades de aprendizagem com desenvolvimento pleno, já que o mesmo atua com conteúdos do cotidiano, como as regras, as interações com o meio e com objetos, além da diversidade de linguagens envolvidas em sua prática.

Kishimoto (2003) argumenta que, através das abordagens teóricas de Piaget (1976) e Vygostsky (1984), é possível ampliar a compreensão sobre os conceitos de jogo, brinquedo e brincadeira e sua relação com o desenvolvimento da aprendizagem.

"Muitas dúvidas persistem entre educadores que procuram associar o jogo à educação: se há diferença entre o jogo e o material pedagógico, se o jogo educativo empregado em sala de aula é realmente jogo e se o jogo tem um fim em si mesmo ou é um meio para alcançar objetivos" (KISHIMOTO, 2003, p. 13).

A concepção da ludicidade no desenvolvimento e na aprendizagem dos educandos, embora distintas, são claramente descritas em ambas as teorias. Os estudos de Piaget (1976) sobre o desenvolvimento e aprendizagem destacam a importância do caráter construtivo do jogo no desenvolvimento cognitivo da criança.

Para Kishimoto (2003) a gradativa percepção de que a manipulação de objetos facilita a aquisição de conceitos introduz a prática de materiais concretos para subsidiarem a tarefa docente.

O ser humano possui um impulso para o jogo e verificou este impulso lúdico já nos primeiros meses de vida, na forma do chamado jogo de exercício sensório-motor; do segundo ao sexto ano de vida, esse impulso lúdico predomina sob a forma dejogo simbólico para se manifestar, a partir da etapa seguinte, através da prática do jogo de regras (RAU, 2011, p. 90).

Segundo Almeida (2003, p. 42), no primeiro ano de vida "a criança desenvolve seus sentidos, seus movimentos, seus músculos, sua percepção e seu cérebro". Esse exercício lúdico resultante de quase todos os esquemas sensórios-motores consiste na repetição de gestos e movimentos simples, com um valor exploratório através da manipulação de objetos, toques e deslocamentos, superpondo, montando e desmontando onde, ao movimentar-se, a criança descobre os próprios gestos buscando efeitos aprimorados com a repetição dos mesmos.

A partir do segundo ano de vida, surgem os jogos simbólicos, dando início às representações e a linguagem, ultrapassando, assim, a simples satisfação da manipulação e assimilando a realidade externa do seu próprio eu, podendo fazer distorções e transposições. $\mathrm{O}$ mesmo é utilizado para encontrar satisfação fantasiosa através do preenchimento de desejos e da superação de conflitos, podendo também agir por meio da compensação.

No jogo simbólico ou de ficção, a satisfação do eu ocorre por meio da transformação do real em função de desejos, desenvolvendo-se com base nos esquemas sensórios-motores de modo em que começam a ser imitados e representados à medida que são compreendidos, criando novas cenas e imitando situações reais por ela vivenciadas. Segundo Piaget (1976), esse “é o caminho para um mundo de faz de conta, que possibilita à criança a realização de sonhos e fantasias, revela conflitos interiores, medos e angústias, aliviando a tensão e as frustrações" (RAU, 2011, p. 92).

A terceira forma de atividade lúdica é marcada pela transição da atividade individual para a socializada, onde os jogos de regras se manifestam por volta dos 5 anos de idade, desenvolvendo-se numa fase que se inicia aos 7 anos de idade, percorrendo até os 12 anos e predominando por toda a vida do indivíduo ao regular e integrar o grupo social. "Os jogos passam a ter uma seriedade absoluta na vida das crianças e um sentido funcional e utilitário" (ALMEIDA, 2003, p. 47).

\footnotetext{
"Os jogos de regras são jogos de combinações sensóriomotoras (corridas, jogos com bolas) ou intelectuais (cartas, xadrez), em que há competição dos indivíduos (sem o que a regra seria inútil) e regulamentados quer por um código transmitido de geração em geração, quer por acordos momentâneos.' (RAU, 2011, p. 93).
}

O autor define ainda uma quarta forma de jogos que possibilitam a reconstrução do real como percepção 
do meio; esta forma é abordada no jogo de construção podendo ocorrer com um objeto, um fato, cenário ou acontecimento, lidando com cenas cotidianas através do faz de conta e com a reflexão sobre as regras que regulam e limitam as relações sociais.

"É a fase escolar em que a criança incorporará os conhecimentos sistematizados, tomará consciência de seus atos e despertará para um mundo em cooperação com seus semelhantes. É interessante considerar os pontos mais significativos de seu desenvolvimento" (ALMEIDA, 2003, p.50).

"As regras refletidas darão ao futuro adulto a possibilidade de se ver em situações que envolvem limites, o que irá ajudá-lo na construção de um sujeito solidário e cooperativo" (RAU, 2011, p.94). A assimilação deste processo se dá por meio do jogo que contribui para o desenvolvimento cognitivo da criança como elemento facilitador. Corroborando tais ideias, Almeida (2003) afirma que as regras são aprendidas concretamente em interação com o grupo, da mesma condição psicossocial.

Já no que diz respeito aos estudos de Vygotsky (1984), "o jogo é considerado um estímulo à criança no desenvolvimento de processos internos da construção do conhecimento e no âmbito das relações com outros" (RAU, 2011, p.95). É através do jogo que a criança transforma os objetos produzidos socialmente pela imaginação. Segundo Vygotsky (1984), toda a atividade lúdica da criança possui regras que demonstram características de comportamento, mesmo que de maneira implícita, sendo o jogo o nível mais alto do desenvolvimento no pré-escolar onde a criança desenvolve comportamentos habituais em sua idade.

Quando novos relacionamentos são criados no jogo entre significações e interações com objetos e ações, o processo de vivenciar situações imaginárias leva a criança ao desenvolvimento do pensamento abstrato, tornando o jogo um elemento fundamental para o desenvolvimento cognitivo.

"O jogo propicia interações e atua na zona de desenvolvimento proximal, possibilitando à criança vivenciar situações que a levam a comportamentos além dos habituais. Para a criança de 0 a 3 anos o objeto se sobrepõe ao significado. A criança precisa ver, tocar e manipular os objetos. Para crianças de 4 a 6 anos o significado se sobrepõe ao objeto. A criança vivencia papéis e situações do seu cotidiano por meio das brincadeiras. Enfim, o jogo é a ação colocada em prática." (RAU, 2011, p. 95)

O jogo deve ser visto como um meio de estímulo cognitivo, social, afetivo, linguístico e psicomotor, além de propiciar aprendizagens específicas no processo de ensino aprendizagem. Assim, ao utilizá-lo como recurso pedagógico na escola, deve-se considerar a organização do espaço físico, a escolha dos objetos e dos brinquedos e principalmente o tempo determinado para a ocupação com o jogo em suas atividades diárias.

O entendimento sobre os aspectos favorecidos pelo lúdico como recurso pedagógico surge como facilitador de diferentes linguagens, verbais e não verbais socializadas e ideologizadas, transformando-se em um instrumento do pensamento. "Ao tratar desse assunto, Vygotsky (1984) defende que a criança necessita de tempo e espaço para identificar e construir sua própria realidade e o faz por meio da prática da fantasia" (RAU, 2011, p. 97).

Os estudos de Kishimoto (2008) apontam a necessidade da criação de espaços como sala de jogos e outros locais que permitam às crianças ter mais liberdade e possibilidades diferentes nos seus movimentos. As áreas de jogos exteriores podem ser anexas a salas de atividade na escola, influenciando favoravelmente a sensibilidade da criança. (RAU, 2011, p. 99)

Segundo Rau (2011), atualmente, há um grande número de educadores que encontram dificuldades em obter espaço e materiais adequados para promover uma prática lúdica na atuação pedagógica dentro da escola, mesmo que este seja reconhecido na prática como meio facilitador da expressão da autonomia, da criatividade, da experimentação, da pesquisa e de aprendizagens específicas.

\section{A Escola, o Educador e o Lúdico}

Segundo Almeida (2003), a Educação Lúdica só é funcional se o educador estiver capacitado a transmitir o conhecimento através da ludicidade. Portanto, se faz necessário um conhecimento profundo sobre os fundamentos que a constituem, condição essencial para socialização do conhecimento.

$\mathrm{Na}$ escola de hoje, a maioria de seus educadores não disponibilizam a educação lúdica para que a criança desenvolva a sua aprendizagem de forma prazerosa. O que vemos na maioria das vezes é um conhecimento transmitido através de estudos rígidos, provas, atividades mecânicas, cerceando a liberdade dos alunos em buscar novos conhecimentos.

"A importância da inserção e da utilização dos brinquedos,
jogos e brincadeiras na prática pedagógica pré-escolar é uma
realidadequeseimpõeaoprofessor. Brinquedos não devemser
explorados somente como lazer, mas também como elemento
bastante enriquecedor para promover a aprendizagem."
(ADAMUZ; BATISTA; ZAMBERLAN, 2011, p.166).

Nessa perspectiva, faz-se necessário que a escola de Educação Infantil recupere o seu verdadeiro sentido, como lugar de alegria, prazer intelectual e satisfação, pois faz parte da sua competência proporcionar a seus alunos 
um ambiente sadio e harmonioso, rico em atividades lúdicas. Deve-se repensar, também, a formação do professor, principalmente, a sua função e competência, não apenas no que tange ao conhecimento teórico, mas numa prática que seja realmente transformadora e que vá ao encontro dos interesses dos alunos. Portanto, os docentes precisam estar conscientes de que a brincadeira para a criança é vital e que traz enormes contribuições no desenvolvimento da habilidade de aprender a pensar.

Portanto, é imprescindível que os professores estejam preparados para atuarem na escola de forma lúdica, pois serão "os animadores, guias, desafiadores e estimuladores de possibilidades". Precisa também ter um bom domínio de conhecimentos específicos, como gostar de trabalhar com crianças. Como bom profissional é fundamental que tenha espírito de pesquisador, buscando conhecimentos novos por meio de leituras, palestras, oficinas etc. (ALMEIDA, 2003, p. 72).

\section{Conclusão}

No transcorrer deste trabalho procuramos nos remeter a reflexões sobre a importância da Educação Infantil para a formação e o pleno desenvolvimento da criança através das atividades lúdicas, mencionando que os jogos, os brinquedos e as brincadeiras na sala de aula podem ser considerados atividades sociais privilegiadas, garantindo a interação, o conhecimento e a construção do sujeito produtor da sua história.É de grande relevância mencionar que o brincar nos espaços educativos precisa estar coligado ao currículo, numa prática que seja realmente transformadora e que vá ao encontro dos interesses dos alunos, sendo necessário pensar também na importância do conhecimento lúdico no processo de formação dos docentes.

\section{Notas}

CORSARO, W. Were friends, right? Inside Kid's cultures. Washington, DC: JosephHenry, 2003.

\section{Referências}

ADAMUZ, Regina Celia;BATISTA, Cleide Victor Mussini; ZAMBERLAN, Maria Aparecida Trevisan. Você gosta de brincar? Do quê? Com quem? In: SANTOS, Santa Maria Pires dos (Org.). Brinquedoteca: a criança, o adulto e o lúdico. Petrópolis/RJ: Vozes, 2000.

ADATTO, Kiku. Conceito de infância passa por transformação. In: O Estado de São Paulo, matéria de Peter Applebome, 25 maio 1998.

ALMEIDA, Paulo Nunes de. Educação Lúdica: Técnicas e Jogos Pedagógicos. 11. ed. São Paulo: Edições Loyola, 2003.

ANTUNES, Celso. Educação Infantil-Prioridade Imprescindível. 5. ed. Petrópolis: Vozes, 2004.

ARIÈS, P. A História social da criança e da família. Rio de Janeiro: Zahar, 1981.
BARBOSA, Maria Carmem Silveira et al. (Orgs). Oferta e Demanda de Educação Infantil no Campo. Porto Alegre: Evangraf, 2012.

BRASIL. Constituição (1988). Constituição da República Federativa do Brasil. Brasília: Senado Federal, 1988.

Referencial Curricular Nacional para a Educação Infantil. Brasília: MEC, Secretaria de Educação Fundamental, 1998. V.1, p.27-28.

Estatuto da Criança e do Adolescente. Lei 8.069/1990. Brasília: Conselho Nacional dos Direitos da Criança e do Adolescente (Conanda) / Ministério da Justiça/Secretaria do estado de Direitos Humanos/ Departamento da Criança e do Adolescente, 2002. p.10

Lei de Diretrizes e Bases da Educação Nacional (9394/96): promulgada em 20 de dezembro de 1996. Apresentação Carlos Roberto Jamil Cury. 7. Ed. Rio de Janeiro: DP\&A, 2007.

.Brasil. Ministério da Educação.Secretaria de Educação Básica. Diretrizes Curriculares Nacionais para a Educação Infantil / Secretaria de Educação Básica. Brasília, MEC, SEB, 2010.

CRAIDY, Carmem Maria; KAERCHER, Gládis (Org.). Educação infantil: pra que te quero? Porto Alegre: Artmed, 2001. p. 24.

COSTA, S. A formação lúdica do professor e suas implicações éticas e estéticas. Psicopedagogia On Line. Educação e saúde mental. Disponível em http://www.psicopedagogia.com.br/artigos/artigo.asp? entrID=692/ Publicado em 28/06/2005. Curitiba: Ibpex, 2005.

DIDONET, Vital. Educação Infantil. Humanidades, Brasília, n, 43, 1991, p. 89-98.

DOLTO, Françoise. La causa de los niños. Buenos Aires: Paidós, 1993

FARIA, Sonimar C.de. História e política da educação infantil. In. FAZOLO, Eliane et al. Educação Infantil em curso. Rio de Janeiro: Ravil, 1997.

FORTUNA, Tânia Ramos. A reinvenção da infância: Pátio Educação Infantil. Porto Alegre: ano II, N6,Dez 2004/Mar 2005.

GAGNEBIN, Jeanne Marie. Infância e pensamento. In: GhiraldelliJR., Paulo. (Org).Infância, escola e modernidade. São Paulo: Cortez, 1997. P. 83-100.

KINCHELOE, J. L. Esqueceram de mim eBad to the Bone: o advento da infância pós-moderna. In: Steinberg, S. R. \& Kincheloe, J. L. (Orgs.).Cultura infantil: a construção corporativa da infância. Rio de Janeiro: Civilização Brasileira, 2001

KISHIMOTO, T. M. (Org.). Jogo, brinquedo, brincadeira e a educação. 11. ed. São Paulo: Cortez, 2003.

KOHAN, Walter Omar. Infância - Entre educação e filosofia. Belo Horizonte:Autêntica, 2005.

KRAMER, Sônia. A Política do Pré-Escolar no Brasil: a arte do disfarce. São Paulo: Cortez, 2001.

MORENO, Gilmara Lupion. Organização do trabalho pedagógico na instituição de educação infantil. In: PASCHOAL, Jaqueline Delgado (Org.). Trabalho pedagógico na educação infantil. Londrina: Humanidades, 2007.

NASCIMENTO, Cláudia Terra do; BRANCHER, Vantoir Roberto; OLIVEIRA, Valesca Fortes de. A Construção Social do Conceito de Infância: algumas interlocuções históricas e sociológicas. Revista Contexto \& Educação, ano 23, n. 79, jan/jun. 2008. Disponível em: https://www.revistas. unijui.edu.br/index.php/contextoeducacao/article/viewFile/1051/802. Acesso em: 15 abr. 2015.

OLIVEIRA, Zilma de Moraes Ramos de. Educação Infantil: fundamentos e métodos. 6 ed. São Paulo: Cortez, 2010.

PIAGET, Jean. Psicologia e Pedagogia. Trad. por Dirceu Accioly Lindoso e Rosa Maria Ribeiro da Silva. Rio de Janeiro: Forense Universitária, 1976.

RAU, Maria Cristina Trois Dorneles. A Ludicidade na educação: uma atitude pedagógica. 2 ed. rev. Curitiba: Ibpex, 2011.

SILVA, Amanda Bertola da. Múltiplas faces da infância: concepções que 
se constroem no mundo contemporâneo.(Graduação) Universidade Estadual de Londrina, 2009.Disponívelem:file:///C:/Users/seven/Downloads/O_ curriculonaeducacaoinfantil\%20(1).pdf. Acesso em: 13 de out. de 2015.

SILVA, Maria Elisandre. A importância da Educação Infantil para o Desenvolvimento e a Aprendizagem da Criança. Trabalho de Conclusão de Curso apresentado ao Curso de Pedagogia da Universidade Estadual de Londrina, 2010. Disponível em: $<$ http://docplayer.com.br/125808-

Maria-elisandre-da-silva-a-importancia-da-educacao-infantil-para-odesenvolvimento-e-a-aprendizagem-da-crianca.html $>$. Acesso em: 05 de out. de 2015.

VYGOTSKY, L. S. Formação Social da Mente.São Paulo: Martins Fontes, 1984 